\title{
Geovivència, el vídeo participatiu per estudiar geografia a l'ensenyament secundari
}

\author{
Jordi Royo Climent
}

Institut Barri Besòs de Barcelona

jorocli@gmail.com

Rebut: juliol de 2017

Acceptat: juliol de 2017

\section{Resum}

La nostra percepció de la situació actual de l'ensenyament de la geografia a secundària i a batxillerat no és positiva, ja que hi predominen uns enfocaments que no interessen a l'alumnat i que projecten una imatge poc útil de la disciplina. Les tecnologies digitals poden oferir un valuós servei a l'educació, i el vídeo participatiu, en particular, és una eina eficient per transmetre conceptes abstractes propis de les ciències socials, com ara la morfologia urbana, la segregació socioespacial, la història d'un barri o la seva memòria històrica. L'article presenta la valoració d'una experiència didàctica on estudiants de tercer i quart d'ESO han realitzat set curtmetratges de manera col-lectiva. El projecte ha permès potenciar dinàmiques transversals $\mathrm{i}$ augmentar la motivació i l'interès dels nois i noies per la geografia.

Paraules clau: didàctica de la geografia; educació secundària obligatòria; TIC-TAC; vídeo participatiu; curtmetratge

Resumen. Geovivència, el vídeo participativo para estudiar geografía en la enseñanza secundaria

Nuestra percepción de la situación actual de la enseñanza de la geografía en la educación secundaria y en el bachillerato no es positiva, porque predominan unos enfoques que no interesan al alumnado y que proyectan una imagen poco útil de la disciplina. Las tecnologías digitales pueden ofrecer un valioso servicio a la educación, y el vídeo participativo, en particular, es una herramienta eficiente para transmitir conceptos abstractos propios de las ciencias sociales, como la morfología urbana, la segregación socioespacial, la historia de un barrio o su memoria histórica. El artículo presenta la valoración de una experiencia didáctica en la que estudiantes de tercero y cuarto de ESO han realizado siete cortometrajes de manera colectiva. El proyecto ha permitido potenciar dinámicas transversales y aumentar la motivación y el interés del alumnado por la geografía.

Palabras clave: didáctica de la geografía; educación secundaria obligatoria; TIC-TAC; vídeo participativo; cortometraje 
Résumé. Geovivència, vidéo participative pour étudier la géographie dans l'école secondaire

Le diagnostic de la situation actuelle de l'enseignement de la géographie dans l'enseignement secondaire n'est pas positif. Les approches dominantes n'intéressent pas les étudiants et projettent l'image d'une discipline inutile. Les nouvelles technologies peuvent fournir un service précieux à l'éducation et en particulier, la vidéo participative est un outil efficace pour transmettre des concepts abstraits spécifiques aux sciences sociales, comme la morphologie urbaine, la ségrégation socio-spatiale, l'histoire d'un quartier ou sa mémoire historique. Voici une évaluation de sept courts-métrages créés collectivement par des étudiants de troisième et quatrième d'ESO. Le projet a permis d'améliorer des dynamiques transversales et d'accroître la motivation et l'intérêt des élèves pour la géographie.

Mots-clés: enseignement de la géographie; enseignement secondaire; TIC; vidéo participative; court-métrage

\begin{abstract}
Geovivència: A participatory video to study geography in secondary school
Our diagnosis of the current situation of teaching geography in Catalan secondary schools is not positive: students seem to show no interest in the subject because the approaches that teachers use do not convey the significance and utility of geography content. We think digital technologies can provide a valuable service to education by reversing this situation. Participatory videos, in particular, are an effective tool to convey abstract concepts of social studies, such as urban morphology, socio-spatial segregation, neighbourhood histories or their historical memory. In this article, we present a critical evaluation of an innovative educational experience carried out in our school that consisted in the creation of seven short films made collectively by third- and fourth-year compulsory secondary education students. The project has allowed us to enhance cross-curricular dynamics and increase students' motivation and interest in geography.
\end{abstract}

Keywords: didactics of geography; compulsory secondary school; ICT; participatory video; short film

\title{
Sumari
}

1. Breu diagnòstic de l'ensenyament tradicional de la geografia a les aules de secundària

2. Les tecnologies digitals: les TIC-TAC
3. Resultats i valoració

Referències bibliogràfiques

\section{Breu diagnòstic de l'ensenyament tradicional de la geografia a les aules de secundària}

El diagnòstic que fem de la situació actual de l'ensenyament de la geografia a secundària i a batxillerat no és positiu. La dificultat d'impartir geografia arrenca, en primer lloc, de la desmotivació de l'alumnat. En un món saturat de comunicacions, en el qual tota la informació es troba a un clic de qualsevol persona, els joves presten menys atenció a entendre el territori i els seus 
problemes. Des del seu punt de vista, l'enfocament que sovint se'ls ofereix a les aules no els interessa, perquè no els aporta coneixements que considerin importants. No hi ajuda, tampoc, el fet que la major part dels professors que imparteixen geografia siguin historiadors. Per manca de formació o d'interès, aquest gruix d'ensenyants es mostra poc interessat en aquesta matèria i tendeix a minimitzar-la dins dels seus temaris.

La pràctica que predomina en la docència de la geografia es basa en el seguiment del llibre de text. Els historiadors, que són més, però també els geògrafs, s'entesten a seguir desenvolupant el currículum en gran mesura a través del text llegit. L'interès que aquests escrits poden despertar en la immensa majoria d'estudiants de l'ESO és nul. Ni els entenen, ni els importa. Si considerem una frase qualsevol d'un llibre de classe (en aquest cas, de tercer d'ESO), ho podrem comprovar:

Les indústries de béns de producció elaboren productes que no es consumeixen directament, sinó que són productes semielaborats, que serveixen com a matèria primera per a unes altres indústries.

Pot interessar una frase així a un adolescent? Li aporta alguna cosa important? Els termes indústria, bé, producció, elaborar i producte són redundants. Tot plegat es refereix a un concepte simple: les indústries creen productes, cosa que qualsevol adolescent sap. ¿Cal fer aprendre la distinció entre indústries de béns de producció, que fabriquen productes semielaborats, i indústries de béns d'ús i consum, que produeixen articles destinats directament al mercat, perquè l'alumnat entengui millor el món? Les fabriques elaboren productes, és obvi i, per tant, no és interessant. Llegir-ho no farà més competent ningú. Si aquest exemple pot semblar absurd, un llibre de text de 200 pàgines pot semblar-ho encara més.

Ja sigui pels llibres de text, per la formació del professorat o per la inèrcia d'una geografia regional arcaica mal combatuda, una gran part de l'ensenyament de la geografia es manté ancorada en compartiments o en calaixos inconnexos: el relleu, els estats, el sector primari, el sector secundari, el sector terciari, la població... En general, els exercicis se centren en preguntes de tipus descriptiu o explicatiu. Els procediments estan en un segon pla, especialment a segon de batxillerat, curs en què les proves de selectivitat preuniversitàries reforcen l'enfocament d'una geografia per calaixos i explicativa. No s'hi contemplen, per exemple, la cartografia (i molt menys els SIG), l'elaboració de gràfics ni el tractament estadístic de dades. Per tant, s'hi aprecia un dèficit d'enfocaments més moderns, com ara l'experimentació, el treball en equip, la recerca, la realització de propostes o la formació en valors. En definitiva, entenem que s'hi projecta una imatge de la disciplina poc útil i no orientada a la resolució de problemàtiques espacials.

\section{Les tecnologies digitals: les TIC-TAC}

Les tecnologies digitals poden oferir un valuós servei a l'educació (Alart et al., 2010). Les TAC (tecnologies per a l'aprenentatge i el coneixement) són 
cada cop més emprades per una part del professorat (si bé és minoritari). No es tracta només de transmetre informació o de divulgar coneixements, sinó també d'entendre que les noves tecnologies incideixen en el propi pensament, en la manera de veure el món i d'entendre'l. L'aplicació de les TAC a la docència és un pas interessant cap a l'evolució d'un nou univers digital, on els joves, més enllà de viure a les xarxes socials, s'adonin que són aquestes les que els ofereixen la capacitat de participar, d'associar-se, d'influenciar en l'entorn i de decidir.

Alguns dels avantatges de les TAC aplicades a l'aula poden ser els següents:

- Permeten adaptar el ritme d'aprenentatge a l'alumnat.

- Estan disponibles independentment de límits horaris o geogràfics.

- Afavoreixen l'accés a continguts reals i adequats al nivell i als interessos de l'alumnat.

- Són adaptables a metodologies diferents: classe magistral, projectes, classe invertida, comunitat d'aprenentatge, etc.

- Potencien la recerca i la selecció d’informació.

- Són útils per al treball en grup.

\subsection{Un exemple pràctic: el vídeo participatiu}

Una de les eines més eficients per a l'apoderament de comunitats és el vídeo participatiu. Utilitzat durant les darreres dècades, especialment entre collectius desfavorits (dones pageses de països pobres, grups d'immigrants o joves de llogarets remots), ofereix avui en dia, i més que mai, la possibilitat d'integrar els joves en el món 2.0 a través de les tecnologies digitals i les xarxes socials.

El curtmetratge pot ser un camí lúdic per transmetre conceptes abstractes propis de les ciències socials, com ara, per exemple, la morfologia urbana, la segregació socioespacial, la història d'un barri i la seva memòria històrica. Aquest tipus d'activitats comprèn un triple valor: el sensitiu, l'emotiu i l'intel-lectual. En realitzar un curtmetratge, l'alumne pren consciència que qualsevol imatge o sèrie d'imatges són una posada en escena, una simulació o una reconstrucció d'uns fets ficticis o reals, fet que l'apropa a l'objectiu de descodificar els missatges implícits o explícits que hi apareixen. No hem d'oblidar, d'altra banda, que la major part de cinema i de televisió que consumeixen els joves d'avui en dia té una alta qualitat tècnica, però una baixíssima qualitat de significats.

El vídeo pot ser el pretext per descobrir els conceptes d'estudi. El procés de desxifrar el llenguatge audiovisual portarà a la necessitat d'abordar, entendre i assimilar els conceptes teòrics o pràctics de les ciències socials. Els vídeos de format curt o curtmetratges són especialment interessants, perquè acostumen a desenvolupar-se a partir d'un únic concepte (enfront dels llargmetratges, tradicionalment més complexos), fet que permet que els joves n'explorin les conseqüències al límit (Graviz, 1994). 
El vídeo participatiu proporciona a l'alumnat un mitjà que li serveix per expressar les seves idees i per fer entendre la seva percepció. Massa sovint, a les aules, s'hi desenvolupen activitats convencionals que prioritzen unes competències i que en refusen d'altres, la qual cosa comporta l'establiment d'un statu quo en el qual els estudiants acaben sent classificats al llarg dels anys de manera força inamovible. Els processos de creacions col-lectives alteren aquests equilibris i ofereixen la possibilitat que alumnes que sempre havien estat refugiats en papers secundaris o a l'ombra d'unes competències poc atractives per a ells destaquin i mostrin les seves habilitats.

Filmar amb dispositius de telèfons mòbils i editar amb qualsevol programari d'un ordinador personal presenta dos avantatges principals: democratitza l'ús del vídeo i permet entrar en ecosistemes urbans on no s'hi podria introduir cap càmera convencional (per exemple: a barris conflictius i a cases particulars), si més no sense que els objectes d'estudi canviessin d'actitud. Finalment, la facilitat per compartir els vídeos a través de les xarxes socials, i en especial de YouTube, constitueix un pas cap a l'apoderament dels joves, especialment en barris desfavorits. No només hauran entès conceptes de la realitat, sinó que també hauran participat a transformar-la.

A continuació, expliquem la metodologia que hem seguit per crear vídeos participatius amb l'alumnat.

\subsubsection{Context}

L'experiència didàctica amb vídeos participatius que volem explicar en aquest article s'ha realitzat a l'institut Barri Besòs, ubicat al barri del Besòs i el Maresme, de Barcelona. Es tracta d'una zona pobra i marginal on la renda familiar és el $54 \%$ de la renda familiar mitjana a Barcelona i on la població amb estudis superiors o CFGS és del 10,4\%, molt per sota de la mitjana de la Ciutat Comtal, que era del 30\% l'any 2016 (Ajuntament de Barcelona, 2017). El més greu de tot és la poca confiança en el futur que mostra el jovent.

L'institut Barri Besòs és públic i recull estudiants de bandes diferents, amb nivells socioeconòmics i hàbits diversos. Una minoria d'estudiants procedeix de Diagonal Mar i del Front Marítim del Poblenou, barri que triplica la renda familiar del Besòs i el Maresme i que acull famílies benestants. El gruix de l'alumnat prové de l'àrea circumdant de l'institut, constituïda per blocs de pisos dels anys setanta edificats per albergar la immigració d'aquella dècada. Tot i que posteriorment s'han construït equipaments i infraestructures nous, les famílies en continuen sent bàsicament pobres. Per últim, una altra part dels nois i noies prové de la Mina (Sant Adrià) i conforma l'alumnat més desvalgut i problemàtic. És en aquest barri on es fan més paleses la misèria, la manca d'oportunitats i l'apropament cap a les activitats delictives.

Per tant, la diversitat present a les aules és enorme. Sovint, a les classes, hi ha més estudiants immigrats que no pas nascuts a l'Estat. Hi predominen els col-lectius del Pakistan, del Marroc i de la Xina. Una classe conflictiva pot comptabilitzar més de cinc-centes expulsions durant un curs. Davant d'aquesta situació, el repte pot ser apassionant. 


\subsubsection{Organització $i$ desenvolupament}

Malauradament, no es facil encabir el vídeo participatiu a l'ensenyament, però és possible. L'estructura hi juga en contra: classes de trenta alumnes, deu assignatures, seixanta minuts per a cada matèria, pressió dels currículums, manca de tradició i poc treball en equip. Tot plegat provoca que, certament, quan es comencen aquests projectes, es tingui la sensació de nedar contracorrent.

Escriure una metodologia sobre com es pot crear un vídeo participatiu seria artificial i poc extrapolable. Per això, a continuació, s'exposen els punts destacats de cada curtmetratge gravat, ja sigui en referència a les dificultats, als punts forts, a l'organització i a la repercussió.

\section{Geovivència 1: La renda diferencial (2015)}

Per ser el primer audiovisual realitzat, va ser el més complicat d'endegar. Calia, abans que res, fer entendre a l'alumnat que faríem un vídeo, que seria participatiu i que serviria per a alguna cosa. A tall de prova, es va dur a terme amb els tres grups de tercer d'ESO (70 alumnes). El pretext per començar-lo va ser el fet d'improvisar amb els objectes de la plaça de Diagonal Mar. De les improvisacions, en van sortir idees que calia desenvolupar, com ara el deteriorament del mobiliari públic i la gran diferència socioeconòmica existent entre els dos costats de la Diagonal. Aquests temes van ser abordats a les classes següents i els estudiants van finalitzar el vídeo amb l'explicació del concepte de la renda diferencial al parc de Diagonal Mar. La valoració va ser molt positiva i va servir, sobretot, per marcar el camí dels curtmetratges posteriors. S’establia una línia, una durada $\mathrm{i}$ un aire reivindicatiu que casava amb els seus interessos. Sorgia una multitud de temes perfectament abordables des de la matèria de geografia que es podien convertir en audiovisuals. A més, el vídeo va ser el guanyador del concurs $\mathrm{BCN}$ Zoom Festival. Els autors van rebre un reconeixement extern que, com que va ser inesperat, va reforçar el projecte de Geovivència.

\section{Geovivència 2: 1717 (2015)}

El segon vídeo es va realitzar paral-lelament al primer, és a dir, dins de la matèria de geografia de tercer d'ESO. En aquest cas, davant la manca d'idees d'algun grup d'alumnes, se'ls va fer l'encàrrec que investiguessin els afusellaments del Camp de la Bota, un tema totalment desconegut per a ells (i per a molta gent del barri) i que els va resultar interessant. Un dels punts forts del vídeo va ser l'empatia històrica que va generar. Calia representar un tema dur d'una forma simple, sense grans actuacions. El fet de posar-se al lloc dels executats i haver de verbalitzar-ne les sensacions i les emocions va ser un mètode magnífic per entendre els presoners polítics i ser capaços de compartir-ne els sentiments mitjançant l'audiovisual. Dins de la recerca, també va ser molt especial entrevistar un testimoni de l'època estudiada. L'intercanvi intergeneracional va ser emotiu i didàctic per totes dues bandes.

\section{Geovivència 3: Barcelona o Sant Adrià (2016)}

El tercer vídeo va ser elaborat dins del marc d'una matèria optativa, per tant, hi van participar menys alumnes, la qual cosa va permetre que ens organitzéssim i 
que ens controléssim millor, però, com es va constatar, un grup petit té menys idees que un de gran. És a dir, es perd una part del potencial creatiu. En aquest cas, s'anava oferint arguments als estudiants a l'espera que sorgissin temes d'interès. En una sessió, com a pretext, se'ls va lliurar un mapa del barri i se'ls va demanar que tracessin l'itinerari que segueixen per arribar als seus domicilis. La sorpresa va ser quan una alumna no trobava casa seva i va descobrir que no vivia a Barcelona, sinó a Sant Adrià. Era l'excusa perfecta per abordar els límits de la ciutat i la metròpoli. S'ha de destacar que va ser el primer vídeo acabat íntegrament pels autors, sense cap mena d'ajuda externa. Aquests tipus de projectes fan possible trobar talents ocults, competències que no s'observen en una classe tradicional i que, en ser descobertes, provoquen un augment de l'autoestima $i$, fins i tot, poden marcar noves orientacions formatives entre alguns joves. Per últim, des del centre cívic Besòs, ens van demanar els vídeos per passar-los a les festes del barri, a la rambla de Prim. Això va facilitar que s'establís un vincle amb el centre cívic a través dels audiovisuals, així com arribar a les persones de l'entorn de l'institut. El vídeo 1717 va impactar especialment entre el col-lectiu de gent gran, qui va protagonitzar escenes emotives. Aquest acte va servir per valorar externament la feina duta a terme pels nois i noies i també va fer prendre consciència en ells mateixos de la importància del que havien fet mitjançant les seves produccions.

\section{Geovivència 4: Buscant la Núria (2017)}

Aquest vídeo es va fer a cavall de la matèria d'història de quart d'ESO i el projecte de recerca. L'inici del programa es va dur a terme sense pretextos. Simplement, en hores de classe, es va demanar als estudiants que sortissin al carrer i que busquessin històries o temes per gravar. Evidentment, això no hagués estat possible sense el bagatge dels tres primers vídeos de Geovivència. En aquest punt, ja al tercer any del projecte, els alumnes sabien que haurien de crear un vídeo $\mathrm{i}$ hi arribaven predisposats. Hi va haver diversos grups que van voler filmar i investigar la història dels solars abandonats. Aquests solars són abundants al barri i se solen omplir d'activitats míseres i delictives. Les imatges podien ser colpidores (naus ocupades, brossa, xeringues), però esdevenia complicat fer-ne una recerca. Alguns vídeos van quedar al calaix, però, a Buscant la Núria, un grup de noies va aconseguir indagar sobre el passat agrícola del barri i tramar una petita història.

\section{Geovivència 5: Ctrl + X (2017)}

Els vídeos anteriors han tingut més o menys repercussió. En resum, alguns dels àmbits on ens consta que han despertat cert interès són els següents: associacions del barri, agrupacions de vídeo social de Barcelona, alguns partits polítics d'esquerra, entorns d'innovació pedagògica i alguna universitat. Un paper importat d'un projecte d'aquest tipus és l'establiment de vincles amb associacions i col-lectius. A través del projecte de recerca La gestión espacial de la conflictividad social: La ordenación urbana de los espacios colectivos y las morfologias arquitectónicas (GECS), col-laborem amb la Universitat de 
Lleida. Els vídeos de Geovivència números 4, 5, 6 i 7 són fruit d'aquesta col-laboració. El titulat $C t r l+X$ s'ha realitzat a partir de textos de Foucault interpretats pels alumnes i a través de filmacions a l'interior de l'edifici. Era interessant la possibilitat de filmar tipologies arquitectòniques o espais conflictius del barri, però amb tot plegat es recollia massa material per enregistrar un curtmetratge.

\section{Geovivència 6: Record d'un malson}

Record d'un malson és, d'alguna manera, un petit secret (fins ara) del barri del Besòs i el Maresme i un deute que teníem amb el nostre entorn immediat. És una virtut del vídeo participatiu la capacitat de contar històries inesperades. Una de les històries més curioses i emblemàtiques del nostre voltant, per les connotacions artístiques, reivindicatives i combatives que comporta, és aquest thriller que uneix personatges com ara l'artista Joan Brossa, l'alcalde franquista Porcioles i un exregidor de l'ajuntament de Sant Adrià. En aquest cas, es va explicar la història a un grup d'alumnes i se'ls va demanar si la trobaven prou captivadora per fer-ne un curtmetratge, com així va ser.

\section{Geovivència 7: Curtmetratge sobre nois xinesos a Barcelona}

El punt fort del darrer vídeo va ser haver convençut un grup d'alumnes xinesos que tenien coses interessants per explicar a causa de la seva procedència. Dins del marc de la matèria d'història, els autors comparen la vida d'un estudiant a la Xina amb la d'un estudiant local i es pregunten per què els seus pares van triar Barcelona i el barri del Besòs i el Maresme per establir-s'hi. Cal destacar que l'elaboració d'aquest curtmetratge ha posat de manifest el paper que hi tenen els mòbils de les últimes generacions, no només en la filmació del material, sinó també en l'edició. Les aplicacions per editar vídeo per a mòbil estan gairebé al nivell de les més usades per a PC (Premier Pro i Sony Vegas Pro, per exemple), fet que ens ha obert una nova via: treballar l'edició en paral-lel — mòbil i PC_, per tal d'aprofitar el potencial de cadascun.

\section{Resultats i valoració}

Ja sigui a través d'aquests exemples o d'altres, el vídeo participatiu pot tenir un paper important, no només amb l'objectiu de dominar el propi ús d'aquestes tecnologies, sinó també com a pretext per treballar conceptes de les ciències socials, motivar, apropar-se a la percepció dels joves, trencar l'estructura rígida $\mathrm{i}$ arcaica de realitzar sis o set sessions seguides en classes tancades, col-laborar en la multidisciplinarietat entre matèries (o projectes) i apropar, en definitiva, professors i alumnes per tal que els primers estiguin més capacitats per entendre $i$ guiar els segons en el seu procés d'aprenentatge cap a una vida activa, participativa, crítica i sensible, en la qual se sentin actors principals per construir un futur millor. 


\section{Referències bibliogràfiques}

Ajuntament de Barcelona (2017). El Besòs i el Maresme: Sant Martí [en línia]. <http://www.bcn.cat/estadistica/catala/documents/barris/70_MA_Besos_ mar_2017.pdf>.

Alart, Núria et al. (2010). Metodologies, eines i estratègies TIC per a una educació multicultural a l'ESO. Barcelona: UOC. Dossiers Did@c-TIC's.

Graviz, Ana (1994). Niños, medios de comunicación y su conocimiento. Barcelona: Herder. 